\title{
Demand Side Management in Small Power Systems - The Estonian Case Study
}

\author{
Imre Drovtar ${ }^{1}$, Argo Rosin ${ }^{1}$, Jako Kilter ${ }^{2}$ \\ ${ }^{I}$ Department of Electrical Engineering, Tallinn University of Technology, \\ Ehitajate tee 5, 19086, Tallinn, Estonia \\ ${ }^{2}$ Department of Electrical Power Engineering, Tallinn University of Technology, \\ Ehitajate tee 5, 19086, Tallinn, Estonia \\ imre.drovtar@ttu.ee
}

\begin{abstract}
The increasing amount of stochastic power generation connected to power system increases the need for additional ancillary reserves. Most of today's electricity consumers are relatively flexible and easily controllable, providing an already existing supplement for traditional power system ancillary services. The flexibility of loads depends on the number, type and size of consumers. In small power systems utilizing loads for power system services pose different challenges for the system operator than in larger systems. The main challenge lies in developing a business case and incentives for the customers to participate in such services. This paper discusses and analyses the Estonian three most energy intensive economic sectors potential for demand side response from a small power system point of view. Generally, it is determined that demand side flexibility provides incentives not only for the power system operator but also for the customer who is able optimize its processes to gain higher economic and energy efficiency and at the same time provide flexibility for the system operator.
\end{abstract}

Index Terms-Load management; power grid; power system management; smart grids.

\section{INTRODUCTION}

According to the European Union's Energy Efficiency Directive article 15.8, all member states are obliged to support access of demand side response (DSR) services providers to the electricity and ancillary service markets. The governmental regulatory institutions for the energy sector together with all market participants are required to work out the necessary technical requirements and parameters for enabling DSR services access to markets [1]. Currently from 28 member states only 5 have regulatory and/or contractual measures that allow or promote different DSR measures to be used for power system control. Finland, Belgium, Austria, Great Britain, Ireland, Germany and France are revising their legislation, which should promote the usage of DSR in those countries [2].

In comparison to the above listed countries, where peak demand can be measured in tens of gigawatts and population in tens of millions, the Estonian power system is a

Manuscript received 16 December, 2015; accepted 26 March, 2016.

This study was supported by the Estonian TSO, Elering AS and the Estonian Ministry of Education and Research (Project SF0140016s11). diminutive compared to them. The Estonian power system is operating in parallel with the integrated and unified power system (IPS/UPS) of Russia. In 2014, the total capacity of installed power plants was $2713 \mathrm{MW}$, and the peak demand has stayed below $1600 \mathrm{MW}$. Together with the other two Baltic States, Latvia and Lithuania, the total system capacity is approximately $6 \mathrm{GW}$ and peak load $5 \mathrm{GW}$.

In the synchronous area of IPS/UPS the frequency control and its related reserves are maintained centrally in Russia. Although there are secondary and tertiary reserves within the Baltic States, then the required capacities are solidarily shared amongst all parties in the synchronous area to keep its operational and maintenance costs low. The increasing share of stochastic and weather-influenced generation in the system inevitably increases the need for additional balancing services to cover the possible mismatches between demand and supply. Using electrical loads as a source of flexibility is one way to solve the need for increasing reserves, however it will be challenging as due to the system's relative size the loads are small in unity and dispersed over the system.

The paper aims to discuss the unused technical potential and willingness from the consumers to provide DSR in small power systems. The results presented in this paper are the outcome of a two year research and cooperation with the Estonian large electricity consumers. Furthermore, as the Estonian power system operates synchronously with other Baltic States power systems, i.e., Latvia and Lithuania, and is in many ways similar, the results and methodologies could be used as basis for future local and regional studies as well.

The paper has been divided into four major sections: the first provides an overview of the previous research and potential of DSR, the second discusses on existing regulation methods and capacities in Estonia, the third provides an assessment of methods used to map the DSR potential in small power systems, and the fourth section discusses and analyses the DSM potential available for power system support. Final section of the paper summarizes the results.

\section{DSR AS A SOURCE OF FLEXIBILITY IN PREVIOUS RESEARCHES}

In this paper the demand side management (DSM) and DSR use a classification according to the ENTSO-E's policy 
paper for DSR [3] published in September 2014. DSR is load demand that can be actively changed by a trigger. DSM is the utilization of DSR for a purpose such as system security (i.e. balancing and congestion), or system adequacy.

Electrical loads are nowadays more predictable and controllable, giving a new opportunity to manage the power system all together through DSM e.g., to prevent outages in power system or participate in the system control (balancing), as well as optimal development of the network [4]-[6]. Torriti et al. in [7] give an overview of the DSR experience in different European countries. Recent developments have reshaped the DSR programs, which are starting to focus on commercial and residential customers rather than industries. For example the Electricite' de France's Tempo tariff is one program that uses different prices according to the weather for small businesses and residential customers [8]. A Danish study determined to aggregate $260 \mathrm{MW}$ (6\% of the Danish peak load) DSR loads from approximately 125000 households with electric heating. The pilot study determined that a household could provide up to $5 \mathrm{~kW}$ of controllable loads per household [9].

Palensky and Dietrich in [10] point out that DSM's main advantage is that it is financially and economically more promising to intelligently control consumers for providing balancing services, than to build new power plants or install energy storage units. Bradley et al. in [11] bring out that deploying DSR in the market can bring positive economic effect and increase the economic welfare for the society. The authors have brought out eight core benefits that DSR can have on the power system e.g., absolute and relative reductions in electricity demand (up to $2.8 \%$ reduction in overall consumption and $1.3 \%$ shift of peak demand in the United Kingdom). In addition, by providing ancillary system services some investments into grid and plants can be displaced. However, large scale participation in DSR may be low without the appropriate sharing of benefits among the parties. In addition, incentives are needed to lower the participation costs in such programs.

\section{A. Services for the Transmission System Operator}

As described in [3] DSR could offer the transmission system operator (TSO) additional ancillary reserve resource to securely integrate weather-influenced generation, maintain security of supply, and optimize the utilization of infrastructure and investments. However, in many cases loads are used as a last resort in emergency situations [3], [12]. On the other hand, investing in additional ancillary services power plants requires large investments into new generation that is needed for its power, not for its produced energy [13]. Besides balancing and shortage of power supply, the increasing renewable integration can lead to regional oversupply and the coinciding frequency and voltage instability problems [14], [15]. The following services through DSM would be of interest for the TSO.

Frequency control. DSR has the potential to cover several frequency reserve requirements. The authors of [15] and [16] bring out that DSR can make a significant and reliable contribution into primary frequency response through dynamic loading. The author in [17] proposes a method to implement industrial loads as frequency restoration reserves
(FRR). FRRs are reserves that relieve frequency containment reserves (FCR) that are fast switching and aim to stabilize the frequency deviation [18]. In another paper [19] an approach for DSM was presented where only the secondary or non-essential loads were shed, i.e. boilers, refrigerators, heating, ventilation, and air conditioning (HVAC). As soon as the disturbance is over, the loads can be smoothly recommitted, skipping long restoration procedures.

Voltage control and stability is mainly affected by load when the power system is unable to meet the demand for reactive power. The phenomenon itself is mainly a local problem in the power system but can lead to system wide incidents [20]. According to [21] load characteristic is one of the most important factors affecting voltage stability. The variety of load types in the system enables the possibility to provide for example seasonal voltage control or other voltage stability related services through DSM.

\section{ESTONIAN POWER SYSTEM REGULATION SERVICES}

System services are technical measures for the electrical power system which ensure the reliability of the system, the security of supply, and power quality. System services include maintaining the frequency, ensuring the existence of reserve capacity, keeping the balance for active and reactive power, regulating voltage and other similar services.

Balancing services are power regulation actions covered by the TSO to balance out the shortfalls and excess of energy due to the actual market situations. These actions also include activating emergency reserves in case of crossborder link failures and generator outages. The services are ordered based on equal terms from the provider who offers the most techno-economically optimal price (pay-as-bid principle).

\section{A. Historical Overview of Regulation Services}

An overview of different regulation services (i.e. regulation capacities, occurrences and costs) is given for the Estonian power system over the period 01.01.2011... 30.10.2014. Although the analysis was done for both, up and down regulation, then it was determined by interviewing potential service providers that from the DSM point only up regulation (i.e. load shedding) is currently possible and therefore under discussion. Figure 1 illustrates the total requirement and total cost distribution for system services through up regulation over the period 2011 to 2014.

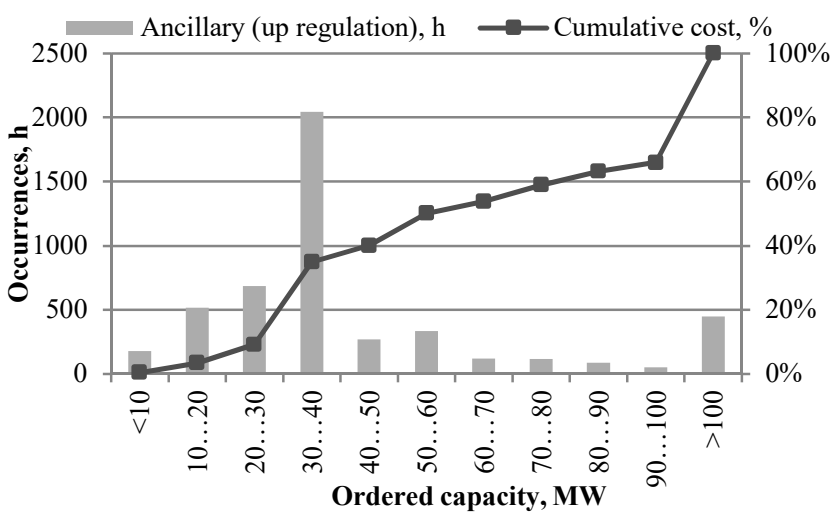

Fig. 1. Up regulation system services occurrences (hours) by capacity and its cumulative cost (\%) over the period 2011-2014. 
System services requirements have varied over the studied period significantly. In 2011 system services were ordered only on 264 hours, the following years, 2012 and 2013, it increased to 1984 and 1877 hours respectively, remaining around 1000 hours in 2014. Majority of the ordered regulations remained below $40 \mathrm{MW}$ and constituted merely $35 \%$ of the total costs on system services through up regulation. The cost of MWh system service has increased over the observable period by $35 \%$ to 71 euros but price variation range has doubled from maximum price of 65 euros to 126 euros.

On the other hand, the requirement for balancing services through up regulation and emergency reserves have stayed on a constant level or even decreased (emergency reserves). Up regulation have occurred around $600 \ldots 700$ hours in a year, 2012 being an exception with 320 hours. At the same time emergency reserve activation has decreased from 953 hours in 2011 to around 100 hours in 2014. Most (86\%) of the ordered regulations remained below $60 \mathrm{MW}$ and constituted $72 \%$ of the total costs for up regulation balancing services over the period from 2011 to 2014 (Fig. 2).

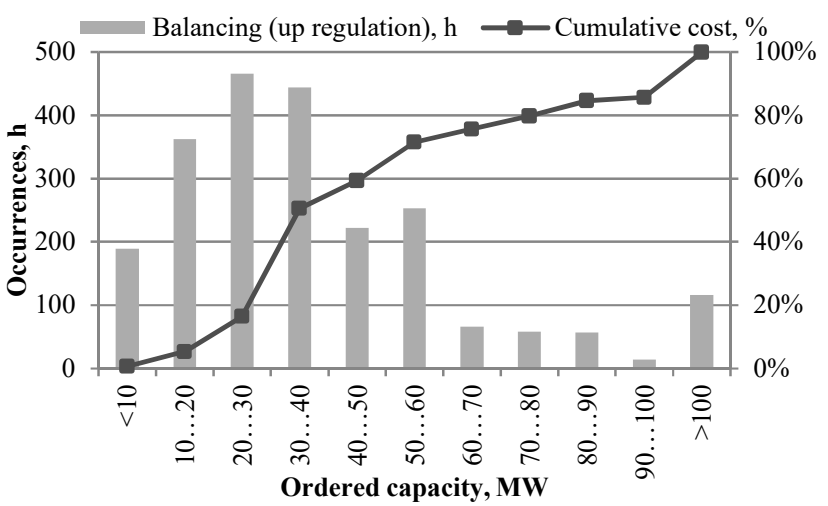

Fig. 2. Up regulation balancing services occurrences (hours) by capacity and its cumulative cost (\%) over the period 2011-2014.

Half (55\%) of the required emergency reserve activations take place at capacities over $60 \mathrm{MW}$ but $47 \%$ of total cost is constituted by regulations over $100 \mathrm{MW}$ (Fig. 3).

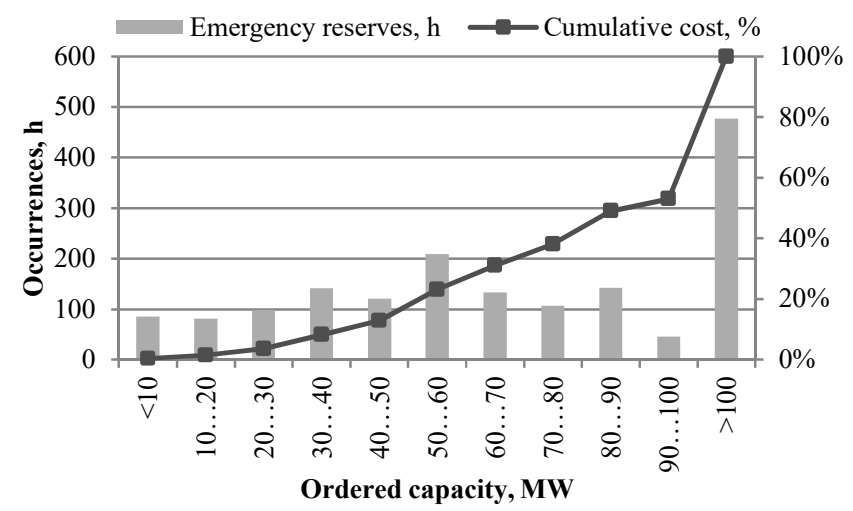

Fig. 3. Emergency reserves activations (hours) by capacity and its cumulative cost (\%) over the period 2011-2014.

The cost of MWh balancing service has not changed significantly over the last four years remaining around 60 euros, also the price variation range does not indicate any significant changes remaining between 30 euros and 100 euros with an exception in 2013 when the price range was between 18 euros and 227 euros. The total cost of emergency reserves on the other hand has decreased compared to 2011 from 4.1 million to 1.4 million euros in 2012 and 2013. The first 10 months of 2014 indicate a further drop, remaining below 0.5 million euros.

From the analysis above it can be deduced that there is already today potential for the consumers to participate either for the balancing service or system service provision. $85 \%$ of the balancing services and more than $60 \%$ of the system services are order by capacities below $60 \mathrm{MW}$ and 40 MW respectively. The cost of these services in the capacity range $40 \ldots 60 \mathrm{MW}$ over the last 4 years was approximately 9 million euros. Although the price per MW is low, the consumers have the possibility and potential to participate in these services.

\section{B. Technical Constraints}

Both, system and balancing services can be in theory also provided by consumers. However, due to technical limitations the Estonian TSO accepts regulating service offers starting from $5 \mathrm{MW}$ (eligible $10 \mathrm{MW}$ ). In addition, all the offers have to be submitted two hours prior to the possible request for service. Single loads with such capacities are very rare in the Estonian power system and usually tied to an industry's main process, thus making it uncontrollable from the customer's point of view. Therefore the necessary load capacities for ancillary services could be aggregated from smaller controllable loads to meet the minimum criteria.

In the commercial sector case, total load shed cannot be discussed as the cost of lost man hours or working days is not rewardable through DSR. It should be noted that as a singular service provider these consumers are a minor players compared to the traditional service providers (i.e. power plants) and in addition the expected reward levels are far from today's market situation where pay-as-bid system is used. Nevertheless, if they could be aggregated on a wider system level and a business case for motivating participation on such market would be in place, they could become quite competitive and eligible service providers.

In addition to the technical constraints, no means to aggregate or verify the ordered services exist. To implement DSR and DSM on a wider scale new information and communications technology together with market platforms need to be developed for controlling and managing these services. The main obstacle for today's market is the service providers' inability to aggregate consumers at any power/energy level to make the provided services easily accessible and verifiable for the necessary parties.

\section{ANALYSIS OF DSR POTENTIAL}

In the following discussion the authors will mainly focus on the DSR in the industry, public and commercial sectors as they are seen as the most eligible service providers. The automation level and infrastructure needed for remote controlling is most probably already installed, meaning a relatively small need for additional investments. Households on the other hand are rather small unit consumers and would require bigger aggregation level and higher investments to provide the services under investigation for the TSO. In 
addition the households' electricity consumption and the willingness to allocate loads for DSR are more influenced by comfort and values rather than technical and economic feasibility. Therefore the analysis of the household consumer would be more of a social research rather than a technoeconomic analysis. This section focuses on the aspects how to determine the DSR potential for different economic sectors where the initial investment for aggregation would be low and other measurable incentives for participation are available.

\section{A. Control Methodology for DSR Loads}

A classical large-scale electricity consumer is usually a business whose sole aim is to produce a profit to its owners. If DSR is deployed and the controllable load is critical for the business, then this might inhibit the primary goal of the business. Therefore, to implement DSR the risk of discomfort for the business owner should be minimized, otherwise the DSR development is halted.

Figure 4 illustrates as an example the results of a production process mapping with production capacity of each sub-process in an industry. As long as the most critical process's operation is guaranteed (in Figure 4 "Process 2"), the rest of the processes can be allocated for DSR. Minimizing the potential risks for the business owner can be achieved by utilizing the built-in intermediate storages as onsite energy storage to shift the electricity consumption of certain parts of the controllable process. The "electrical" storage capacity of such units is determined by the physical size of the intermediate storage and its coherence with the following sub-process [22]. The bigger the production capacity and the following intermediate storage of the optimizable sub-process are compared to the consecutive process, the longer it is possible to deploy DSR in that process.

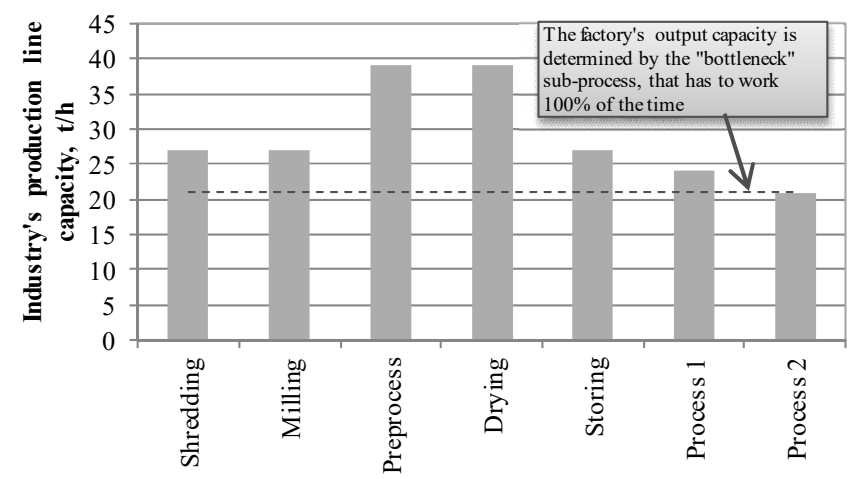

Fig. 4. Controllable loads and their potential for DSR.

Over the course of a related research [22], the authors determined a linear correlation between electricity consumption and product output in industries $\left(\mathrm{R}^{2}=0.79\right)$. The authors in [23] determined similar association between temperature and electricity consumption with a correlation factor $\mathrm{R}^{2}=0.87$. In addition, it was stated that a $0.55^{\circ} \mathrm{C}$ (or $1{ }^{\circ} \mathrm{F}$ ) change in freezer zone air temperature would change the energy consumption of the analysed freezers air handler by approximately $50 \mathrm{kWh}$. At the same time other studies e.g., [24] and [25] suggest an energy saving potential between $2 \% \ldots 10 \%$ with a 1 degree $\left({ }^{\circ} \mathrm{C}\right)$ temperature change. As there are not many processes to shift in the commercial and public institutions the main storage possibilities and therefore DSR potential lie in thermal storage and temperature control. These interdependencies provide the necessary bases for determining potential business cases for the consumers to motivate them participating in DSR and DSM.

\section{B. Business Cases for DSR}

In comparison to larger power systems, where DSR is measured in hundreds of megawatts and the rewarding system is in thousands of euros per megawatt, small power systems, such as Estonia, do not have the financial or technical potential to work on the same concepts. The business case for the Estonian customer should be based on other principles than the direct financial motivation of DSR and ancillary services markets in large power systems. Example business cases for different economic sectors are described in the following subsections.

\section{Wood Industry}

Depending on the produced goods, electricity cost can make up to $4 \% \ldots 12 \%$ of the manufacturing costs of the final product in the wood industry [26], [27]. One of the most perspective DSR measures is optimizing the factory's electricity costs according to the spot market price. This is considered to be one of the key elements lowering the production costs in the industry. The authors of [22] have determined that the electricity cost $(E)$, which is a stochastic parameter, for a single load under investigation can be minimized according to scenarios s with (1)

$$
\min _{Q_{t}} \sum_{s} \sum_{t} P_{t}^{s} \times C^{L}\left(Q_{t}\right) \times P(s)+C^{E}\left(Q_{t}\right)
$$

where $P_{t}$ is the electricity price for time period $t, C^{L}$ is the output power of the load depending on the production volume $Q_{t}, P(s)$ is the probability of scenario $s$, and $C^{E}$ is the external cost of the load shifting e.g. start-up costs, labor costs and etc.

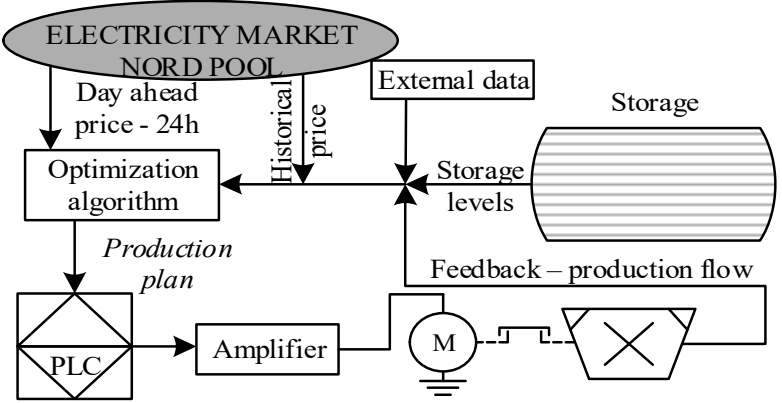

Fig. 5. A simplified production control with day-ahead optimization of the machines' operation schedule.

Two scenarios have been analysed for an industry. In the first scenario the production plan was adjusted according to the historical market prices. Since actual spot price dips and peaks might not be in the determined range and time then the second approach utilizes in addition the day-ahead price information. This enables the industrial consumer to use the most optimal production plan for the specific day. A simplified production control philosophy is illustrated in 
Figure 5.

The authors of [22] determined that by applying the optimization according to the historical market price data, the load's annual electricity costs could be lowered up to $11 \%$. However, when implementing additionally the dayahead market price optimization algorithm according to (1), the specific electricity cost of the studied sub-process could be lowered as much as $17 \%$ compared to the base case. The same load control principle could be then applied for providing DSM.

\section{Office Buildings and Shopping Centers}

In the public (office buildings) and commercial (shopping centers) sector the business case is built solely on the concept of covering administrative charges (heating and ventilation related) through price based load control. Price based HVAC control is based on the principle that at higher price periods the air flow to the rooms is reduced or the cooling element is allowed to work at higher set-points e.g. the room temperature is kept between $20{ }^{\circ} \mathrm{C} \ldots 26^{\circ} \mathrm{C}$ [28]. In case of controlling water heaters the water in the boilers has to be kept at least $55{ }^{\circ} \mathrm{C} \ldots 60{ }^{\circ} \mathrm{C}$ to prevent bacteria from growing [29].

The temperature control algorithm checks the actual hourly price against the last 24 hours average price. If the prices are equal, no control is performed, however if there is a price difference a new set-point is determined [30]. In shopping centers' the most probable controllable load was determined to be the central cooling station for the freezers and refrigerators, all other electrical loads (i.e. lighting, and etc.) were considered either as essential for operation or marginal to the possible effects.

The main constraint for DSM arises from the issue that loads allocated for DSR could be only switched to lower consumption profile in order to maintain the work of essential equipment and assure the minimal requirements for the safety, working environment and the comfort of the employees. However, it was determined that utilizing additionally a cold storage, the flexibility of freezers could be increased threefold.

\section{DISCUSSION OF DSM POTENTIAL}

Based on the interviews with the customers and analysis of the consumption data, the controllable loads are divided into three categories based on the industrial consumers. This assures that the customer would bare minimal losses when implementing DSM. Similar classification of loads will be used also to describe the other consumers potential for DSM.

"Freely" controllable load (FCL) is the load of the processes that can be allocated for DSM measures at any time. In the case of industrial consumer the load depends strongly on the load factor of the electrical machines, remaining around $50 \% \ldots 60 \%$ from rated power $\left(P_{N}\right)$ for mechanical processes and can be calculated as follows

$$
P_{F C L}^{D S M}=\sum_{m=1}^{n}\left(\sigma_{m} \times P_{N, m}\right),
$$

where $n$ is the total number of electrical drives in the process, $\sigma_{m}$ represents the loading factor of the specific drive and $P_{N, m}$ is the rated power of the specific drive.

"Conditionally" controllable load (CCL) is the load of the processes that can be controlled under certain conditions or at certain times. This load depends from the process that runs with variable load, increasing under certain conditions the FCL service provision up to $40 \%$. CCL can be calculated as follows

$$
P_{C C L}^{D S M}=\sum_{m=1}^{n}\left[\left(1-\sigma_{m}\right) \times P_{N, m}\right]
$$

“Exceptionally" controllable load (ECL) takes into account also loads that under normal condition are not controllable and can be allocated for control under extreme conditions i.e. load shedding during emergencies in the power system or when the service price is high enough to cover the expenses occurring with DSM measures.

\section{A. Paper and Wood Industry}

The main precondition for industrial consumers to partake in DSM is that the final production is not affected by it e.g. due to storage capacities after the controllable loads. The analysed wood industry's rated and theoretical potential for providing DSM measures with durations according to available storage capacities is summarized in Table I.

\begin{tabular}{|c|c|c|c|c|}
\hline \multirow{2}{*}{$\begin{array}{c}\text { Load } \\
\text { shift, h }\end{array}$} & \multicolumn{3}{|c|}{$\begin{array}{c}\text { Estimated capacity (\% of average } \\
\text { consumption) }\end{array}$} & \multirow{2}{*}{$\begin{array}{c}\text { Total } \\
\text { from } \\
\text { average } \\
\text { load }\end{array}$} \\
\hline & $\begin{array}{c}\text { FCL, } \\
\text { MWh/h }\end{array}$ & $\begin{array}{c}\text { CCL, } \\
\mathrm{MWh} / \mathrm{h}\end{array}$ & $\begin{array}{c}\text { ECL, } \\
\mathbf{M W h / h}\end{array}$ & \\
\hline 1 & $1.58(66 \%)$ & $0.79(33 \%)$ & $1.75(73 \%)$ & $173 \%$ \\
\hline 2 & $1.58(66 \%)$ & $0.79(33 \%)$ & 0.00 & $99 \%$ \\
\hline $2-71$ & $1.07(45 \%)$ & $0.45(19 \%)$ & 0.00 & $64 \%$ \\
\hline $72-144$ & $0.39(16 \%)$ & $0.26(11 \%)$ & 0.00 & $27 \%$ \\
\hline
\end{tabular}

TABLE I. DSM POTENTIAL IN THE WOOD INDUSTRY.

Based on the carried out interviews, analysis and measurements the authors estimate that on average the whole paper and wood industry could engage at least $20 \%$ from their average electricity consumption in DSR, this estimation is also is affirmed in [31]. The study [31] brings out that every company in the Estonian wood and forestry sector has on average $27 \%$ free unused production capacity $(\delta)$. This enables the industry to increase its production output for short periods of time higher than the usual production capacity, making it ideal for DSR and DSM.

From the available electricity consumption data for the wood and paper industry the total DSM potential can be then calculated. The calculations are based on the assumption that the industry is operated in a 24/7 regime and the DSM potential is calculated based on the industry's average hourly electricity consumption. These assumptions guarantee that the calculated capacities are available for short terms of period, i.e. $1 \ldots 2$ hours. The possible DSM potential of the whole industry is calculated as follows

$$
\overline{P_{\text {Industry }}^{D S M}}=\frac{\delta}{m \times n} \sum_{j=1}^{m} \sum_{i=1}^{n} P_{i, j},
$$

where $m$ represents the number of industries in the sector, $n$ is the total number of hours used to determine average electricity consumption, $P_{i, j}$ represents the total electricity consumption for $n$ hours at $m$ industry companies, and $\delta$ is 
the reserve production capacity factor.

According to the estimation (4) it is possible that the Estonian wood industry can provide on average at least 22 MW of ancillary services and paper industry $8 \mathrm{MW}$. Results are summarized in Table II.

TABLE II. DSM POTENTIAL IN THE WOOD INDUSTRY.

\begin{tabular}{|l|c|c|c|}
\hline & Estimated capacity, MWh/h (\% of average load) \\
\hline & FCL & CCL & ECL \\
\hline Paper & $8(\mathbf{2 1} \%)$ & $3(\mathbf{8 \%})$ & $25(\mathbf{6 3 \%})$ \\
\hline Wood & $22(\mathbf{6 6} \%)$ & $11(33 \%)$ & $25(\mathbf{7 4 \%})$ \\
\hline
\end{tabular}

A rough estimation of DSM amongst Estonian industrial consumers is given by using (4). The estimation is based on the following assumptions:

- the industrial consumers are in continuous operation (24/7),

- the average hourly consumption is based on their total electricity consumption from public databases [32],

- the load is eligible for DSR for minimum 1 hour,

- the production lines are at least $20 \%$ under loaded.

From this it can be estimated that the Estonian industrial sector would be additionally able to provide FCL up to $35 \mathrm{MW}$ for ancillary services to the TSO through DSM.

\section{B. Office Buildings}

The DSM potential is based on the flexible load capacity factor $\varphi$ as calculated in (5) and denotes the loads that can be flexibly controlled. Based on the electricity consumption of similar office buildings the possible DSM potential for $8 / 5$ and $24 / 7$ building is calculated according to (6):

$$
\begin{aligned}
& \phi=\frac{1}{n} \sum_{i}^{n} \frac{P_{i}^{1}+P_{i}^{2}+\ldots+P_{i}^{m}}{P_{i}^{\text {total }}}, \\
& \overline{P_{S C}^{D S M}}=\frac{\phi}{p \times o} \sum_{k=1}^{p} \sum_{j=1}^{o} P_{k, j},
\end{aligned}
$$

where $n$ is the total number of hours used to determine average electricity consumption, $m$ represents the number of different types of flexible loads available for control, $P_{i}^{\text {total }}$ represents the total electricity consumption at hour $n$, $P_{i}^{l} \ldots P_{i}^{m}$ represents the total flexible load at hour $n, \varphi$ is the flexible load capacity factor, $p$ represents the number of office building in the sector, $o$ is the total number of hours used to determine average electricity consumption, $P_{k, j}$ represents the electricity consumption for $o$ hours at $p$ office buildings. The estimation (6) indicates that the Estonian public services sector would be able to provide for ancillary services over a period of 1 hour on average up to $86 \mathrm{MW}$ of regulating power. Results are summarized in Table III.

TABLE III. TOTAL ESTIMATED DSM POTENTIAL IN OFFICE BUILDINGS (OB).

\begin{tabular}{|c|c|c|}
\hline \multirow{2}{*}{$\begin{array}{c}\text { Duration of the } \\
\text { control (h) }\end{array}$} & \multicolumn{2}{|c|}{ FCL (\% of average load) } \\
\cline { 2 - 3 } & $\mathbf{8 / 5}$ OB, MWh/h & $\mathbf{2 4 / 7}$ OB, MWh/h \\
\hline $\mathbf{1}$ & $72(73 \%)$ & $14(14 \%)$ \\
\hline $\mathbf{2 \ldots .}$ & $24(25 \%)$ & $2.3(2 \%)$ \\
\hline
\end{tabular}

\section{Shopping Centres}

The study determined that using a cold storage and controlling the ventilation system according to the price, it would be possible to provide ancillary service power in shopping centers up to 2 hours and $34 \%$ from the average consumption capacity. For a period of $3 \ldots 8$ hours it would be possible to allocate $24 \%$ from the average consumption capacity and $9 \ldots 13$ hours approximately $16 \%$ from the average consumption capacity. The total DSM potential with or without cold storage can be estimated in a similar manner as for office buildings with (5) and (6). The results are summarized in Table IV.

TABLE IV. TOTAL ESTIMATED DSM POTENTIAL IN SHOPPING CENTRES.

\begin{tabular}{|c|c|c|c|c|}
\hline $\begin{array}{c}\text { Duration of } \\
\text { the control } \\
\text { (h) }\end{array}$ & \multicolumn{2}{|c|}{$\begin{array}{c}\text { Flexibility } \\
\text { with storage (\% of } \\
\text { average consumption) }\end{array}$} & $\begin{array}{c}\text { Flexibility } \\
\text { without storage (\% of } \\
\text { average consumption) }\end{array}$ \\
\cline { 2 - 5 } & $\begin{array}{c}\text { FCL, } \\
\text { MWh/h }\end{array}$ & $\begin{array}{c}\text { ECL, } \\
\text { MWh/h }\end{array}$ & $\begin{array}{c}\text { FCL, } \\
\text { MWh/h }\end{array}$ & $\begin{array}{c}\text { ECL, } \\
\text { MWh/h }\end{array}$ \\
\hline $\mathbf{1 \ldots 2}$ & $26(\mathbf{3 4} \%)$ & $8(\mathbf{1 0} \%)$ & $7(\mathbf{9} \%)$ & $9(\mathbf{1 2} \%)$ \\
\hline $\mathbf{3 \ldots 8}$ & $18(\mathbf{2 4} \%)$ & $8(\mathbf{1 0} \%)$ & 0 & $9(\mathbf{1 2} \%)$ \\
\hline $\mathbf{9 . . 1 3}$ & $13(\mathbf{1 6} \%)$ & 0 & 0 & $1(\mathbf{2} \%)$ \\
\hline
\end{tabular}

It should be noted that due to nature of the controlled loads demand shifting with cold storage would increase the additional power requirement and thus the average electrical consumption outside the DSM measure timeframe 1.5 times.

\section{CONCLUSIONS}

The possibilities to use different consumers' loads for DSR and DSM were discussed. An analysis of the Estonian power system regulation services indicated that although there are some technical limitations for implementing DSM then actually it is already today possible to incorporate electricity consumers to the system service provision. Majority of the required capacities remain below $40 \mathrm{MW}$ ...60 MW. The analysed samples of loads could possibly provide a high durational range of services for the TSO. The total DSM potential estimation is summarized in Table $\mathrm{V}$.

TABLE V. TOTAL ESTIMATED DSM POTENTIAL IN ESTONIA.

\begin{tabular}{|l|c|}
\hline \multicolumn{1}{|c|}{ Sector } & $\begin{array}{c}\text { Average controllable load in one } \\
\text { hour, MWh/h (\% of average } \\
\text { consumption) }\end{array}$ \\
\hline Industry & $65(\mathbf{2 6 \%})$ \\
\hline Offices $(24 / 7)$ & $14(\mathbf{1 4 \%})$ \\
\hline Offices $(8 / 5)$ & $72(\mathbf{7 3 \%})$ \\
\hline Wholesale and retail buildings & $7 \ldots 26(\mathbf{9 . . 3 4 \% )}$ \\
\hline TOTAL & $\mathbf{1 5 8 . . . 1 7 7}(\mathbf{1 8 . . . 2 0 \% )}$ \\
\hline
\end{tabular}

The largest potential for DSM is seen in the industrial sector, due to the relatively large unit consumers that can be allocated for aggregated control comparatively easy. In addition, the industry's production line is usually segmented allowing more flexibility for control. Also the high level of automation in the industry allows performing aggregation with relatively low costs. It is estimated that controllable DSR load in the industry can be around $65 \mathrm{MW}$, from what approximately half originates from the wood and paper industry. The controllable load potential in the commercial and institutional services sector (shopping centres and office buildings) remain between $93 \mathrm{MW} .112 \mathrm{MW}$, depending on whether cold storage is implemented or not. This $93 \mathrm{MW}$ can be provided steadily throughout the year. The largest potential constitutes from $8 / 5$ type office buildings. 
The analysis indicates that if DSR could be implemented for providing system services, the potential of DSM would be in the range of $160 \mathrm{MW} . .180 \mathrm{MW}$. The analysis determined that the average price for emergency, ancillary and balancing reserves in Estonia has stayed in the recent years between 50 euros...80 euros per MWh and it occurs around 2200 times (hours) per year. In the assumption that on average up to $150 \mathrm{MW}$ of DSR capacities could be provided for the region's ancillary services markets at least 1 hour...3 hour a day, then only the Estonian DSM market value would be up to 13 million euros.

Future work will focus on the analysis and modelling of possible voltage control related DSM services in small power systems. The aim of the study should determine the potential influence of load related voltage regulation services for the TSO. These should be at least in theory economically more feasible alternatives for voltage regulating devices that are required seasonally or on rare occasions.

\section{REFERENCES}

[1] Directive 2012/27/EU of the European Parliament and of the Council of 25.10.2012 on energy efficiency. [Online]. Available: http://eur-lex.europa.eu/

[2] A Demand Response Action Plan For Europe, Smart Energy Demand Coalition (SEDC), Brussels 2013 [Online]. Available: http://sedccoalition.eu/

[3] Demand Side Response Policy Paper, ENTSO-E, 15. Sept. 2014 [Online]. Available: https://www.entsoe.eu

[4] M. Paulus, F. Borggrefe, "The potential of demand-side management in energy-intensive industries for electricity markets in Germany", Applied Energy, vol. 88, no. 2, pp. 432-441, 2011. [Online]. Available: http://dx.doi.org/10.1016/j.apenergy.2010.03.017

[5] M. Paulus, F. Borggrefe, "Economic potential of demand side management in an industrialized country - the case of Germany", in 10th IAEE European Conf., Vienna Austria, 2009.

[6] O. Malik, P. Havel, "Analysing demand-side management potential: Situation in Europe and the Czech Republic", in Proc. 2011 10th Int. Conf. Environment and Electrical Engineering (EEEIC), pp. 1-4, 2011. [Online]. Available: http://dx.doi.org/10.1109/EEEIC.2011. 5874781

[7] J. Torriti, M.G. Hassan, M. Leach, "Demand response experience in Europe: Policies, programmes and implementation", Energy, vol. 35, no. 4, pp. $1575-1583,2010 . \quad$ [Online]. Available: http://dx.doi.org/10.1016/j.energy.2009.05.021.

[8] J. Vasconcelos, "Survey of regulatory and technical development concerning smart metering in the European Union electricity market", RSCAS Policy Paper 2008/01, Florence School of Regulation. Florence: European University Institute; 2008.

[9] M. Andersen, S. Grenaa Jensen, V. Larsen, P. Meibom, H. Ravn, KSkytte, et al., "Analyses of demand response in Denmark", Risø, RAM-løse edb. Copenhagen: Ea Energy Analyses, 2006.

[10] P. Palensky, D. Dietrich, "Demand side management: demand response, intelligent energy systems, and smart loads", in IEEE Trans. Industrial Informatics, vol. 7, no. 3, pp. 381-388, 2011. [Online]. Available: http://dx.doi.org/10.1109/TII.2011. 2158841

[11] P. Bradley, M. Leach, J. Torriti, "A review of the costs and benefits of demand response for electricity in the UK", Energy Policy, vol. 52, pp. 312-327, 2013. [Online]. Available: http://dx.doi.org/10.1016/j. enpol.2012.09.039

[12] Estonian national Grid Code, 2014 [Online]. Available: https://www.riigiteataja.ee/akt/12831412?leiaKehtiv (in Estonian)

[13] "How can flexible capability be rewarded in the electricity markets of the future?" A Public Report, February 2014, Pöyry Management Consulting (UK) Ltd. [Online]. Available: http://www.poyry.com

[14] M. Negnevitsky, V. Kurbatsky, N. Tomin, D. Panasetsky, "Intelligent approach for preventing large-scale emergencies in electric power systems," in Proc. of IEEE PowerTech 2013, Grenoble, France, 2013. [Online]. Available: http://dx.doi.org/10.1109/PESMG. 2013.6672099
[15] S. Weckx, J. Driesen, R. D'hulst, "Optimal frequency support by dynamic demand", in Proc. of IEEE PowerTech 2013, Grenoble, France, 2013. [Online]. Available: http://dx.doi.org/10.1109/PESMG. 2013.6672099

[16] A. Molina-Garcianda, F. Bouffard, D. Kirschen, "Decentralized demand-side contribution to primary frequency control", IEEE Trans. Power Systems, vol. 26, no. 1, pp. 411-419, 2011. [Online] Available: http://dx.doi.org/10.1109/TPWRS.2010.2048223

[17] D. Fabozzi, N. F. Thornhill, B. C. Pal, "Frequency restoration reserve control scheme with participation of industrial loads", in Proc. of IEEE PowerTech 2013, Grenoble, France, 2013. [Online]. Available: http://dx.doi.org/10.1109/PTC.2013.6652104

[18] Operational reserve ad hoc Team report. Final version, ENTSO-E, 23/05/2012. [Online]. Available: https://www.entsoe.eu

[19] Y. Tofis, L. Hadjidemetriou, E. Kyriakides, "An intelligent load shedding mechanism for maintaining frequency stability", in Proc. of IEEE PowerTech 2013, Grenoble, France, 2013. [Online]. Available: http://dx.doi.org/10.1109/PTC.2013.6652296

[20] P. Kundur, Power System Stability and Control, New York, 1994.

[21] J. Duan, J. Huang, "The mechanism of voltage instability analysis considering load characteristic", in Energy and Power Engineering, 2013, vol. 5, pp. 1497-1502. [Online]. Available: http://dx.doi.org/10.4236/epe.2013.54B283

[22] P. Uuemaa, I. Drovtar, A. Puusepp, J. Kilter, A. Rosin, J. Valtin, "Cost-effective optimization of load shifting in the industry by using intermediate storages", in Conf. Proc. IEEE ISGT Europe, Copenhagen, Denmark, 2013. [Online]. Available: http://dx.doi.org/10.1109/ISGTEurope.2013.6695404

[23] D. Woradechjumroen, H. Li, Y. Yu, "Energy Interaction among HVAC and Supermarket Environment", World Academy of Science, Engineering and Technology International Journal of Civil, Structural, Construction and Architectural Engineering, vol. 8, no. 12, 2014. [Online]. Available: waset.org/publications/9999881

[24] J. Palmer, N. Terry, P. Pope, "How much energy could be saved by making small changes to everyday household behaviours?", A report for Department of Energy and Climate Change, UK. Cambridge Architectural Research 2012. [Online]. Available: https://www.gov.uk/government/publications/

[25] N. El-Sayed, I. A. Stefanovici, G. Amvrosiadis, A. A. Hwang, B. Schroeder, "Temperature management in data centers: why some (might) like it hot", in Proc. of the 12th ACM SIGMETRICS/PERFORMANCE joint Int. Conf. Measurement and Modeling of Computer Systems, ACM, New York, USA, pp. 163174. [Online]. Available: http://www.cs.toronto.edu/\%7Eioan/papers/ SIGMETRICS2012.pdf

[26] O. Espinoza, B. H. Bond, U. Buehlmann, "Energy and the US hardwood industry - Part I: Profile and impact of prices", BioResources, vol. 6, no. 4, pp. 3883-3898, 2011. [Online] Available: http://ojs.cnr.ncsu.edu/index.php/BioRes/article/view/ BioRes_06_4_3883_Espinoza_BB_Energy_US_HW_Ind_Pt1_Profil e_Prices

[27] Ecorys Research and Consulting, "Study on European EnergyIntensive Industries - The Usefulness of Estimating Sectoral Price Elasticities", Methodological Review, First Interim Report for the Directorate-General Enterprise \& Industry. ENTR/06/054. Cambridge, UK, 2009.

[28] "Indoor environmental input parameters for design and assessment of energy performance of buildings addressing indoor air quality, thermal environment, lighting and acoustics", Standard EN 15251:2007, European Committee for Standardization (CEN).

[29] United States Department of Labor. Occupational Safety and Health Administration (OHSA). Facts and Frequently Asked Questions on Legionnaire's Disease. [Online.]. Available: https://www.osha.gov/ $\mathrm{dts} /$ osta/otm/legionnaires/faq.html

[30] L. Aleixo, A. Rosin, H. Saele, A. Z. Morch, O. S. Grande, I. Palu, "Ecogrid EU project - Real time price based load control and economic benefits in a wind production based system", Electricity Distribution (CIRED 2013), 22nd Int. Conf. Exhibition on, Stockholm, 2013, pp. 1-4. [Online]. Available: http://dx.doi.org/10.1049/cp.2013.1253

[31] Sector Research of the Estonian Wood- and Forrest Industry 2012, Final Report, Tallinn University of Technology, Institute of Baltic Studies 17.06.2013. (Original title: Eesti metsa- ja puidutööstuse sektoruuring 2012, Uuringu lõpparuanne.). (in Estonian)

[32] Statistics Estonia, Database: FE061. [Online]. Available: http://pub.stat.ee/px-web.2001/Dialog/statfile1.asp 